\title{
NIZHAMIYAH
}

JurnalPendidikanIslamdanTeknologiPendidikan

Vol. VIII,No1,Januari- Juni 2018

ISSN2086-4205

\section{BELAJAR MENGENAL BANGUN DATAR DENGAN MENGGUNAKAN PERMAINAN TRADISIONAL ENGKLEK / ENGKRANG}

\author{
Rora Rizky Wandini ${ }^{1} \&$ Ahcmad Rafi ${ }^{2}$
}

\begin{abstract}
Abstrak : Permainan engklek atau engkrang ini adalah suatu pemain tradisional yang dimana anak anak dahulu bermain dengan cara melemparkan gacok atau kuntil kedalam kolom kolom yang kosong dimana kolom tersebut dimainkan dengan cara diangkat kaki satu tanpa memijak gacok kita yang berada didalam kolom yang lain,permain ini juga bermacam macam pariasi, dari pariasi dimana yang berbentuk rumah, bentuk lemari dan ada juga berbentuk manusia, maka pembahasan hari ini kita menggunakan permainan engklek dengan bentuk manusia. Dan permainan ini akan dikombinasikan dalam pembelajaran mengenal bagun datar. Tujuannya adalah untuk mengingat dan menambah pengetahuan anak tentang bangun datar dengan cara bermain agar anak dapat mengimplementasikan dikehidupan sehari hari sehingga ketika mereka memainkan permainan ini maka daya ingat mereka tentang bangun datar itu lebih cepat ditangkap selain itu mengingatkan anak pada permainan permainan tradisional. Permainan ini dapat dikombinasikan dengan berbagai macam strategi, dan dalam tulisan ini akan dikombinasikan dengan strategi CTL (Contextual Teaching Learning).
\end{abstract}

Kata Kunci : Permainan tradisional engklek/ engkrang, Strategi CTL (Contextual Teahing Learning)

\section{A. PENDAHULUAN}

Pada umumnya guru mengajarkan matematika, dengan menerangkan konsep dan operasi matetematika, memberi contoh, mengerjakan soal, serta meminta siswa untuk mengerjakan soal yang sejenis dengan soal yang sudah diterangkan guru. Menurut Fruendhental : 1973 dalam Rostina, pembelajaran tersebut merupakan model mekanistik yaitu guru menekankan pembelajaran matematika bukan pada pemahaman siswa terhadap konsep dan operasinya, melainkan pada pelatihan symbol-simbol matematika dengan penekanan pada pemberian informasi dan latihan penerapan algoritma. Guru bergantung pada metode ceramah, siswa yang pasif, sedikit tanya jawab, dan siswa mencatat di papan tulis.

Menurut Van de Henvel-Panhuizen : 2000 dalam Zainurie : 2007, bila anak belajar matematika terpisah dari pengalaman mereka sehari-hari maka anak akan cepat lupa dan tidak dapat mengaplikasikan matematika. Djamarah : 2013 menjelaskan di dalam kegiatan belajar mengajar ketidakjelasan bahan yang disampaikan dapat dibantu dengan menghadirkan media perantara. Kerumitan bahan pelajaran dapat disederhanakan dengan bantuan media dan mengkombinasikan beberapa strategi pembelajaran.

Salah satu strategi pembelajaran yang dapat diberikan adalah CTL. CTL sendiri merupakan konsep belajar yang mendorong guru untuk menghubungkan antara materi yang diajarkan 
dan situasi dunia nyata siswa. Pada materi bangun datar pembelajaran yang disajikan menggunakan strategi CTL yang dikombinasi dengan permainan tradisional engklek/ engkrang. Permainan engklek atau engkrang ini adalah suatu pemain tradisional yang dimana anak anak dahulu bermain dengan cara melemparkan gacok atau kuntil kedalam kolom kolom yang kosong dimana kolom tersebut dimainkan dengan cara diangkat kaki satu tanpa memijak gacok kita yang berada didalam kolom yang lain,permain ini juga bermacam macam pariasi, dari pariasi dimana yang berbentuk rumah, bentuk lemari dan ada juga berbentuk manusia, maka pembahasan hari ini kita menggunakan permainan engklek dengan bentuk manusia

Tulisan ini mencoba memberikan deskripsi tentang hal-hal yang diketahui, dipahami, dan diimplementasikan dalam penggunaan strategi pembelajaran matematika khususnya CTL yang dikombinasikan dengan permainan tradisional engklek/ engkrang pada materi bangun datar.

\section{B. PEMBAHASAN}

\section{Pengertian CTL (Contextual Teaching Learning)}

Blanchard (Trianto, 2007) mengemukakan bahwa pembelajaran kontekstual adalah pembelajaran yang terjadi dalam hubungan yang erat dengan pengalaman sesungguhnya. Sejalan dengan Blanchard, Muslich (2007) menjelaskan bahwa landasan filosofi CTL adalah konstruktivisme, yaitu filosofi belajar yang menekankan bahwa belajar tidak hanya sekadar menghafal tetapi mengkonstruksi atau membangun pengetahuan dan keterampilan baru lewat fakta-fakta yang mereka alami dalam kehidupannya. Dengan mengacu pada beberapa pendapat di atas, pembelajaran CTL merupakan suatu konsep pembelajaran yang mengaitkan antara materi pelajaran yang dipelajari siswa dengan konteks di mana materi tersebut digunakan dengan menggunakan pengalaman dan pengetahuan sebelumnya untuk menemukan dan membangun pengetahuannya sendiri. Materi pelajaran akan bermakna bagi siswa jika mereka mempelajari materi tersebut melalui konteks kehidupan mereka.

Menurut Jonhson (2009) CTL adalah sebuah proses pendidikan yang bertujuan untuk menolong para siswa melihat siswa melihat makna didalam materi akademik yang mereka pelajari dengan cara menghubungkan subyek-subyek akademik dengan konteks dalam kehidupan keseharian mereka. 
Jadi, dapat disimpulkan bahwa Pembelajaran kontekstual (Contextual Teaching andLearning) adalah "konsep belajar yang membantu guru mengaitkan antara materi yang diajarkannya dengan situasi dunia nyata siswa dan mendorong siswa membuat hubungan antara pengetahuan yang dimilikinya dengan penerapannya dalam kehidu-pan mereka sehari-hari, dengan melibatkan tujuh komponen utama pembelaaran efektif, yakni: konstruktivisme (constructivism), bertanya (questioning), menemukan (inquiri), masyarakat belajar (learning community), pemodelan (modeling), dan penilaian sebenarnya (authentic assessment)".

\section{Komponen CTL (Contextual Teaching Learning)}

Beberapa komponen utama dalam pembelajaran Kontekstual menurut Johnson (2009), yang dapat di uraikan sebagai berikut:

1. Melakukan hubungan yang bermakna (Making Meaningful Connections)

Keterkaitan yang mengarah pada makna adalah jantung dari pembelajaran dan pengajaran kontekstual. Ketika siswa dapat mengkaitkan isi dari mata pelajaran akademik, ilmu pengetahuan alam. Atau sejarah dengan pengalamannya mereka sendiri, mereka menemukan makna, dan makna memberi mereka alasan untuk belajar. Mengkaitkan pembelajaran dengan kehidupan seseorang membuat proses belajar menjadi hidup dan keterkaitan inilah inti dari CTL.

2. Melakukan kegiatan-kegiatan yang berarti (Doing Significant Works)

Model pembelajaran ini menekankan bahwa semua proses pembelajaran yang dilakukan di dalam kelas harus punya arti bagi siswa sehingga mereka dapat mengkaitkan materi pelajaran dengan kehidupan siswa.

3.Belajar yang diatur sendiri (Self-Regulated Learning)

Pembelajaran yang diatur sendiri, merupakan pembelajaran yang aktif, mandiri, melibatkan kegiatan menghubungkan masalah ilmu dengan kehidupan sehari-hari dengan cara-cara yang berarti bagi siswa. Pembelajaran yang diatur siswa sendiri, memberi kebebasan kepada siswa menggunakan gaya belajarnya sendiri.

\section{Bekerjasama (collaborating) Siswa dapat bekerja sama.}

Guru membantu siswa bekerja secara efektif dalam kelompok, membantu siswa bekerja secara efektif dalam kelompok, membantu mereka memahami bagaimana mereka saling mempengaruhi dan saling berkomunikasi.

5. Berpikir kritis dan kreatif (Critical dan Creative Thinking) 
Pembelajaran kontekstual membantu siswa mengembangkan kemampuan berpikir tahap tinggi, nerpikir kritis dan berpikir kreatif. Berpikir kritis adalah suatu kecakapan nalar secara teratur, kecakapan sistematis dalam menilai, memecahkan masalah menarik keputusan, memberi keyakinan, menganalisis asumsi dan pencarian ilmiah. Berpikir kreatif adalah suatu kegiatan mental untuk meningkatkan kemurnian, ketajaman pemahaman dalam mengembangkan sesuatu.

6. Mengasuh atau memelihara pribadi siswa (Nuturing The Individual)

Dalam pembelajaran kontekstual siswa bukan hanya mengembangkan kemampuankemampuan intelektual dan keterampilan, tetapi juga aspek-aspek kepribadian: integritas pribadi, sikap, minat, tanggung jawab, disiplin, motif berprestasi, dsb. Guru dalam pembelajaran kontekstual juga berperan sebagai konselor, dan mentor. Tugas dan kegiatan yang akan dilakukan siswa harus sesuai dengan minat, kebutuhan dan kemampuannya.

7. Mencapai standar yang tinggi (Reaching High Standards)

Pembelajaran kontekstual diarahkan agar siswa berkembang secara optimal, mencapai keunggulan (excellent). Tiap siswa bisa mencapai keunggulan, asalkan sia dibantu oleh gurunya dalam menemukan potensi dan kekuatannya.

\section{Menggunakan Penilaian yang otentik (Using Authentic Assessment)}

Penilaian autentik menantang para siswa untuk menerapkan informasi dan keterampilan akademik baru dalam situasi nyata untuk tujuan tertentu. Penilaian autentik merupakan antitesis dari ujian stanar, penilaian autentik memberi kesempatan kepada siswa untuk menunjukkan kemampuan terbaik mereka sambil mempertunjukkan apa yang sudah mereka pelajari.

\section{Langkah- langkah pembelajaran CTL}

Menurut bahwa secara garis besar penerapan pendekatan kontekstual dapat dilakukan dengan langkah-langkah sebagai berikut( Suparto, 2004: 6):

1) Mengembangkan metode beajar mandiri,

2) Melaksanakan penemuan (inquiry),

3) Menumbuhkan rasa ingin tahu siswa,

4) Menciptakan masyarakat belajar,

5) Hadirkan "model" dalam pembelajaran,

6) Lakukan refleksi di setiap akhir pertemuan,

7) Lakukan penilaian yang sebenarnya 


\section{NIZHAMIYAH}

JurnalPendidikanIslamdanTeknologiPendidikan

Vol. VIII,No1,Januari- Juni 2018

\section{ISSN2086-4205}

\section{Permainan Tradisional Engklek/ Engkrang}

Permainan ini sudah lama sekali di mainkan oleh anak-anak usia sekolah dasar, baik putra maupun putri. Permainan ini sangat sederhana sekali. Tetapi dapat mengembangkan keterampilan gerak dasar pada anak-anak. Permainan ini lebih banyak menekankan pada aktivitas melompat. Tujuan dari permainan ini adalah mengembangkan keterampilan gerak dasar melompat, mengembangkan koordinasi antara tangan dan mata. Cara bermainya

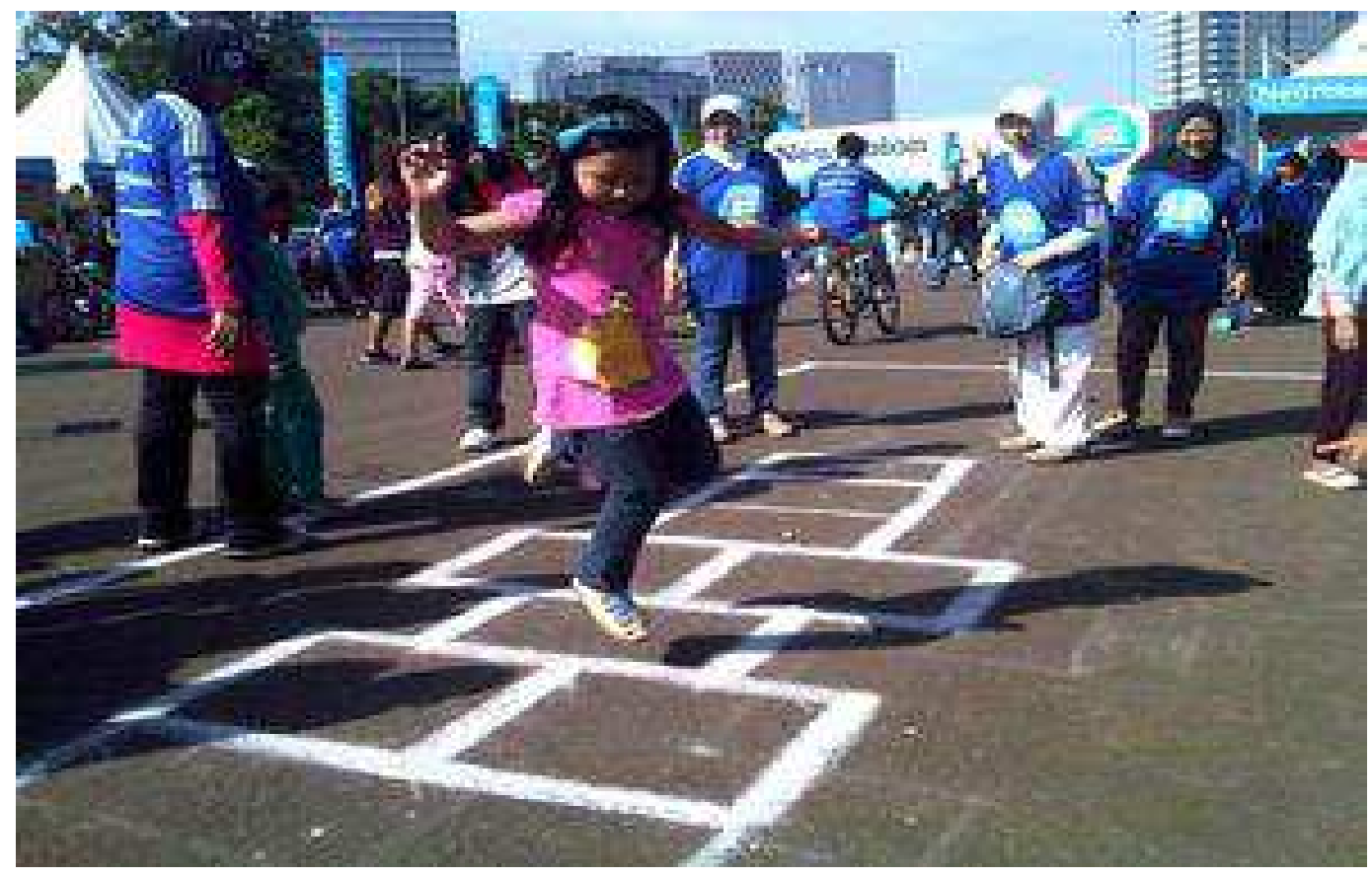

pertama kita menggambar di atas tanah ataupun di jalan 8 kotak dan setengah lingkaran di bagian atas sendiri. Lalu kita beri nomor pada masing kotak. Kemudian yang digambar setengah lingkaran itu diberi nomor sembilan dan dibagian setengah lingkarannya diberi nomor sepuluh. Seperti gambar dibawah ini :

\section{Alat-alat dan bahan:}

- $\quad$ Tanah lapang yang berukuran kurang lebih 6 x 4 meter.

- $\quad$ Pecahan genteng atau keramik

- $\quad$ Sebatang lidi

\section{Cara bermain:}

- Membuat gambar gunungan terlebih dahulu di atas tanah yang rata dan tidak ada kerikil atau yang dapat membuat kaki cidera.

- $\quad$ Setelah membuat bentuk lapangannya, kemudian siapkan pecahan genteng atau keramik sejumlah anak yang akan bermain. 
- $\quad$ Sekitar 5 orang peserta, telah siap dengan tanda atau biasa disebut dengan gacuk (pecahan genteng atau keramik tadi) di kotak nomor 1.

- $\quad$ Peserta di undi untuk mendapatkan giliran kesempatan untuk bermain.

- $\quad$ Peserta yang mendapatkan giliran pertama siap untuk melompat dengan satu kaki secara urut tiap kotak kecuali kotak nomor 4 dan 6 peserta meletakkan kedua kakinya baik kanan maupun kiri pada kedua kotak tersebut di nomor 4 dan 6. (kotak yang terdapat gacuk tidak boleh di lompati tetapi harus di lewati dengan melangkahinya) Peserta tidak boleh menginjak garis.

- $\quad$ Setelah sampai di nomor 6, peserta berbalik dengan meloncat dan melompat kembali lagi pada posisi awal. Sebelum kembali ke posisi awal, peserta harus mengambil gacuknya terlebih dahulu.

- Ketika peserta berhasil kembali ketempat semula, ia harus melanjutkan permainan lagi dengan melemparkan gacuknya ke kotak nomor berikutnya. Dan selanjutnya melakukan lompatan lagi sampai kembali hingga sampai ke nomor 6 yang di sebelah kiri.

- Untuk kotak nomor 4 dan 6 peserta harus meletakkan gacuknya di mulai dari sebelah kanan. Apabila gacuknya terletak di sebelah kanan pada kotak nomor 4, peserta harus mengambilnya dari kotak nomor 4 di sebelah kiri, begitu pula sebaliknya.

- Bila sampai pada nomor 7, peserta harus mengambil dengan berbalik arah/ mengambil dengan mata tertutup. Tangan atau badannya tidak boleh menyentuh garis.

- $\quad$ Peserta yang berhasil sampai pada nomor 7, ketika kembali pada posisi semula harus melemparkan gacuknya di luar busur singkaran. Peserta melompat lagi dan hingga nomor 6 , nomor 7 tidak boleh di lompati. Ia harus meraih dengan menginjak gacuknya dengan satu kaki, apabila berhasil peserta harus melemparkan lagi ke posisi semula dan kembali lompat di mulai peserta menginjak gacuknya ke kotak nomor 6 sampai kotak nomor 1.

- $\quad$ Sesampainya di kotak nomor 1, peserta harus menginjak gacunya lagi dengan kedua kakinya. Apabila gagal, peserta harus mengulanginya dari nomor 6 ketika ia mendapatkan giliran kembali.

\section{Manfaat permainan}

1. Mengembangkan keterampilan gerak dasar melompat dan meloncat yaitu dengan melompati tiap kotak dari nomor 1 hingga nomor 7. 
2. Mengembangkan koordinasi mata dan tangan, secara otomatis ketika peserta akan melemparkan gacuknya ia menggunakan insting yang kuat agar gacuknya tepat pada kotak yang di inginkan.

3. Melatih otot tungkai, sehingga akan didapat kaki yang terkuat. Permainan ini baik sekali untuk melatih anak-anak dalam atletik lompat jauh, lompat jangkit bahkan lompat tinggi.

4. Melatih kejujuran, apabila kakinya meyentuh garis maka peserta dinyatakan gugur dan menunggu giliran berikutnya.

\section{Penerapan strategi CTL dengan Permainan Tradisional Engklek/ Engkrang Pada Materi Bangun Datar}

Sebelum bermain guru harus menjelaskan tentang bangun datar beserta rumus, ada pun yang menjadi permainan ini adalah tidak semuanya bangun datar, hanya beberapa bangun saja, seperti, lingkaran, persegi panjang, persegi, segitiga, dan jajar genjang atau belah ketupan yang akan dibuat sebagai kaki dari tengkoyak / permainan engklek manusia ini.

\section{Persegi}

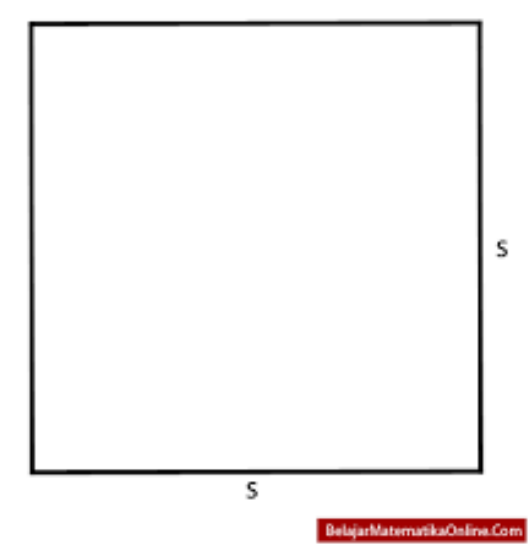

Luas $=\mathbf{s} \times \mathbf{s}$

Keliling $=4 \times \mathrm{s}$

Ket :

$\mathrm{S}=$ sisi 


\section{Persegi Panjang}
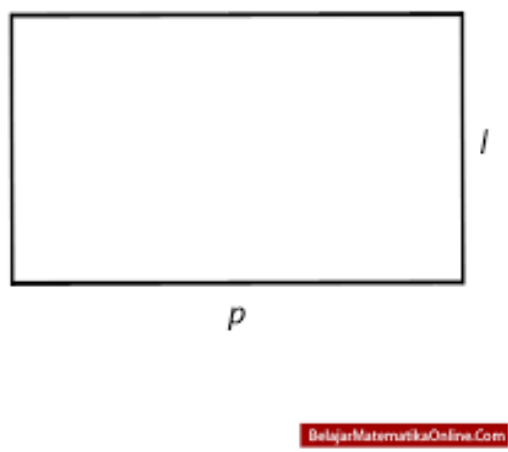

Luas $=p \times 1$

Keliling $=2 \times(p+1)$

Ket :

$\mathrm{P}=$ panjang

$\mathrm{L}=$ lebar

3. Segitiga
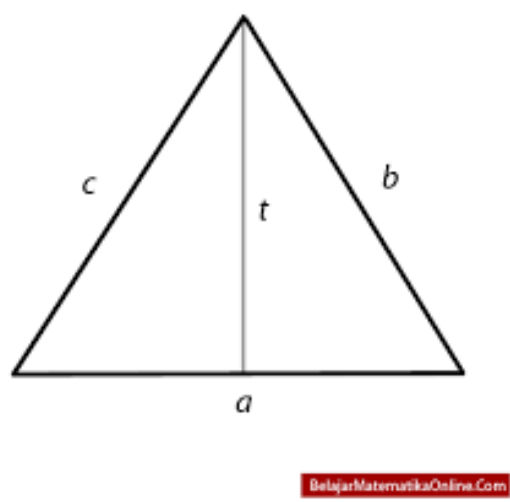

luas $=1 / 2 \times$ a $\times$ t

keliling $=\operatorname{sisi} \mathrm{a}+\operatorname{sisi} \mathrm{b}+\operatorname{sisi} \mathrm{c}$

ket :

$\mathbf{a}=$ alas

$\mathbf{t}=$ tinggi 


\section{Jajar genjang}

Keliling $=2 \mathrm{x}($ sisi $\mathrm{a}+\operatorname{sisi} \mathrm{b})$

Ket :

$\mathrm{A}=$ alas

$\mathrm{T}=$ tinggi

\section{Layang - Layang}
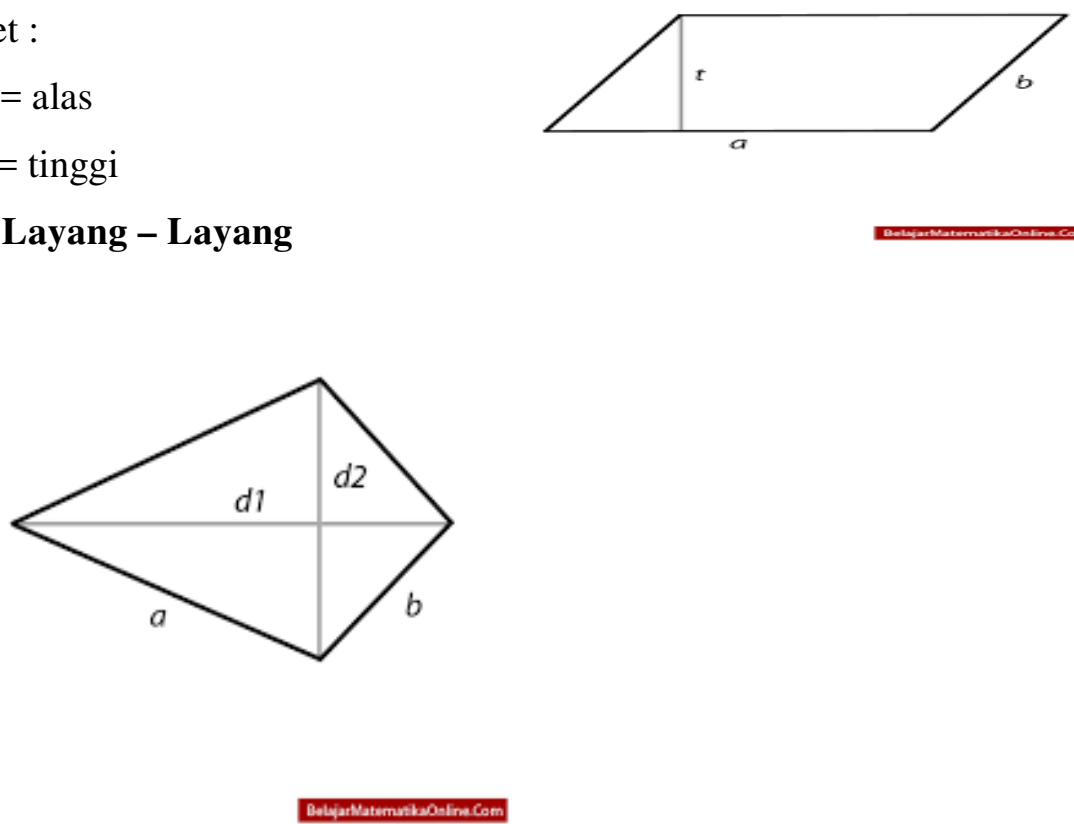

Luas $=1 / 2 \times \mathrm{d} 1 \mathrm{xd} 2$

Keliling $=2 \mathrm{x}($ sisi $\mathrm{a}+\operatorname{sisi} \mathrm{b})$

Ket :

D1 = diagonal 1

D2 = diagonal 2

\section{Belah ketupat}

Luas
Ket :
D1 =
D2 =

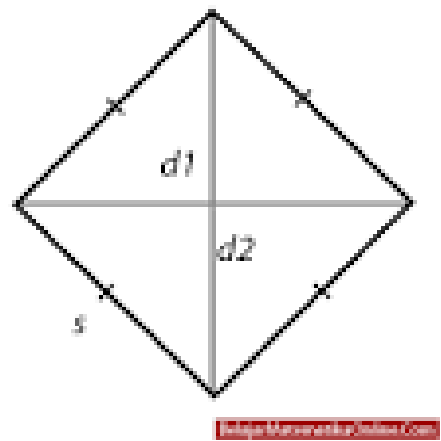

$=1 / 2 \times \mathrm{d} 1 \times \mathrm{d} 2$

Keliling $=4 \mathrm{x}$ sisi

diagonal 1

diagonal 2

\section{Trapezium}

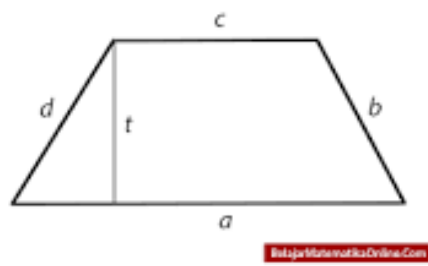


Luas $=1 / 2 \times(a+c) \times t$

Keliling $=\operatorname{sisi} \mathrm{a}+\operatorname{sisi} \mathrm{b}+\operatorname{sisi} \mathrm{c}+\operatorname{sisi} \mathrm{d}$

Ket :
a : alas
c : sisi yang sejajar dengan alas

\section{Lingkaran}

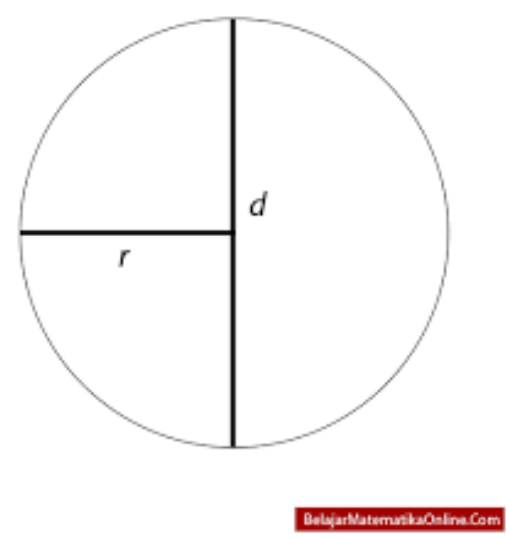

Luas $=\mathrm{TT} \times \mathrm{r} \times \mathrm{r}$

Keliling $=2 \times$ TT $\times \mathrm{r}=$ TT $\times \mathrm{d}$

Ket :

$\mathrm{r}=$ jari - jari

$\mathrm{d}=$ diameter
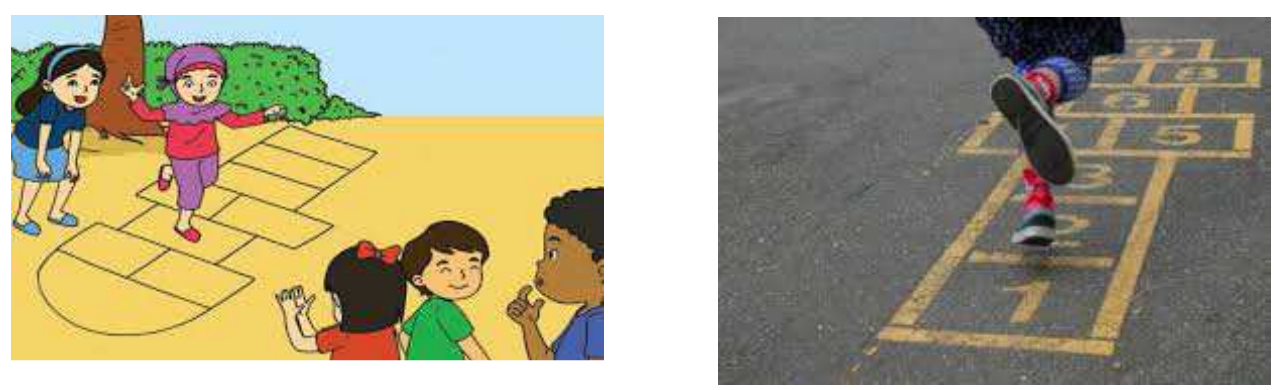

Pada gambar diatas permainan engklek ini bisa dikombinasikan kepada bangun datar apa saja sesuai dengan kreatifitas anak, dan boleh juga diberi angka supaya bisa di ingat di nomor berapa gacok kita berada. 
*Engklek manusia dalam matematika*

Kepala $=$ lingkaran

Tangan kiri $=$ persegi panjang

Tangan kanan $=$ persegi panjang

Perut $=$ persegi

Paha kanan dan kiri $=$ segitiga

Dan kaki $=$ jajaran genjang

CARA BERMAIN :

a. Pemain melakukan hompimpa yang menang berhak melakukan permainan terlebih dahulu. Pemain pertama melemparkan gaco ( pecahan enternit di kotak nomor satu ). Saat melemparkanny tidak boleh melebihi kotak yang telah disediakan jika melebihi maka dinyatakan gugur.

b. Pemain pertama melompat dengan satu kaki ( engklek), dari kotak I sampai kotak 6 kemudian berhenti sejenak dikotak A kemudian kembali lagi dengan mengambil gaco yang ada di kotak satu dengan posisi kaki satu masih di angkat.

c. Setelah itu pemain melemparkan gaco tersebut sampai ke kotak 2 jika keluar dari kotak 2 maka pemain dinyatakan gugur dan diganti oleh pemain berikutnya.

d. Begitu seterusnya sampai semua kotak sudah dilempar dengan gaco. Pergiliran dilakukan jika pemain pelempar gaco melewati sasaran, atau menampak 2 kaki di kotak 1,2,3,4,5,6 dan berhenti sejenak dikotak A kemudia lompat lagi di kotak 3 dan berhenti di kotak 2 untuk mengambil gaco dikotak 1.

e. Jika gaco berada di kotak 2 maka pemain mengambilnya dikotak 3, jika gaco berada di kotak 4,5 dan 6 maka pemain mengambilnya di kotak A.

f. Kemudian jika semua telah dilakukan oleh semua pemain maka pemain melemparkan gaco dengan membelakangi engkleknya jika pas pada kotak yang dikehendaki maka kotak itu akan menjadi rumahnya maka boleh berhenti dikotak tersebut seperti pada kotak A tapi hanya berlaku pada pemain yang menang pada permainan tersebut begitu seterusnya sampai kotak kotak dari angka 1 sampai 6 menjadi milik para pemain. Jika telah dimiliki oleh sang pemain maka permainan dinyatakan telah selesai.

g. Pemenang adalah pemain yang paling banyak memiliki rumah dari kotak kotak pada engklek. 
Demikianlah permainan engklek manusia yang dikombinasikan pada bangun datar, harapannya anak lebih mengenal bangun datar dengan cara bermain permainan tradisional ini.

\section{KESIMPULAN}

Dalam permainan ini diharapkan siswa lebih beraktifitas dalam belajar dan dapat memahami pembelajaran secara cepat, dan permainan ini ditujukan kepada kelas kelas renda, dengan bermain anak lebih menyenangkan dan tidak boring atau suntuk dalam pembelajaran mengingat matematika adalah pembelajaran yang paling extrim yang berada disekolah, maka untuk pengajar pengajar yang berada disekolah dasar atau MI hendaknya mempunyai ke kreatifan dalam membuat materi, dan skill juga di perlukan dalam proses belajar mengajar, dana pembelajaran mengenal bangun datar melalui engklek ini juga bisa diaplikasikan dalam kehidupan sehari hari dan anak juga tidak terlupa dengan permainan zaman dahulu.

\section{DAFTAR PUSTAKA}

B. Johnson. Elaine .2009. Contextual Teaching and Learning. Terj. Ibnu Setiawan. Bandung: Mizan Learning Center.

Djamarah. 2008. Strategi Belajar Mengajar. Jakarta: Rieneka Cipta

Muslich. Mansur. 2007. KTSP.Pembelajaran Berbasis Kompetensi dan Kontekstual. Jakarta: PT. Bumi Angkasa

Rostina.S.2016. Media dan Alat Peraga dalam Pembelajaran Matematika. Bandung : Alfabeta Trianto. 2007. Model-model Pembelajaran Inovatif Beririentasi Konstruktivistis. Jakarta : Prestasi Pustaka.

Suparto. 2004. Penerapan Contextual Teaching and Learning dalam Kurikulum Berbasis Kompetensi. Semarang : Depdiknas Dinas P dan K Provinsi Jawa Tengah.

Zainure. 2007. Pembelajaran Matematika Realistic. http://Zainure.wordpress.com.2007/04/13/ pemb. Matematika realistic.rme/. diakses tgl 28-22018. Pukul 11.00 wib.

http://idebermainanak.wordpress.com/tag/engklek. Diakses tgl 28-2-2018. Pukul 10.57 wib 